Jurnal Penelitian Pendidikan IPA (JPPIPA)
P-ISSN : 2460-2582 | E-ISSN : 2407-795X
Sekretariat $\quad:$ Lt. 3 Gedung Pascasarjana Universitas Mataram
Telp./Fax $\quad:$ (0370) 634918
Email $\quad:$ jppipa@ unram.ac.id
Website $\quad:$ http://jppipa.unram.ac.id/index.php/jppipa/index

\title{
PENGARUH JENIS MULSA DAN DOSIS BOKASHI TERHADAP PERTUMBUHAN KACANG PANJANG (Phaseolus vulgaris L)
}

\author{
AHMAD RAKSUN ${ }^{1}$, LALU JAPA ${ }^{2}$ \\ ${ }^{1}$ Program Studi Pendidikan Biologi, Universitas Mataram, Email: ahmadunram@unram.ac.id \\ ${ }^{1}$ Program Studi Pendidikan Biologi, Universitas Mataram, Email: ljapa@unram.ac.id
}

Accepted: September 22 $2^{\text {st }}, 2018$. Approved: October 10 ${ }^{\text {st }}, 2018$. Published: November $17^{\text {st }}, 2018$ DOI: $10.29303 /$ jppipa.v5i1.155

\begin{tabular}{|c|c|}
\hline Key Words & Abstract \\
\hline $\begin{array}{l}\text { Mulch, bokashi, } \\
\text { growth, long } \\
\text { bean }\end{array}$ & $\begin{array}{l}\text { Research about the effect of different types of mulch and dosage of bokashi on the } \\
\text { growth of long bean has done in Sukarara village Central Lombok. The purpose of } \\
\text { conducting research are (1) to identify the effect of different types of mulch on the } \\
\text { long bean growth, (2) to identify the effect of bokashi on the long bean growth, (3) } \\
\text { to identify the effect of interaction betwen different types of mulch and dosage of } \\
\text { bokashi on the long bean growth. In this research, factorial design was used } \\
\text { consisting of } 2 \text { factors. The first factor is the type of mulch and the second factor is } \\
\text { the dosage of bokashi. The data was analyzed using Anova and least significant } \\
\text { differens test (LSD).The result showed that: (1) different types of mulch have no } \\
\text { significant effect on the growth of long bean, (2) bokashi dosage has a significant } \\
\text { effect on long bean growth, (3) interaction of mulch types and bokashi dosage did } \\
\text { not significantly effect long bean growth. }\end{array}$ \\
\hline Kata Kunci & Abstrak \\
\hline $\begin{array}{l}\text { Mulsa, bokashi, } \\
\text { pertumbuhan, } \\
\text { kacang pajang }\end{array}$ & $\begin{array}{l}\text { Penelitian tentang pengaruh jenis mulsa dan dosis bokashi terhadap pertumbuhan } \\
\text { kacang panjang, telah dilaksanakan di Desa Sukarara Kabupaten Lombok Tengah. } \\
\text { Tujuan dilaksanakannya penelitian ini adalah untuk mengetahui: (1) pengaruh jenis } \\
\text { mulsa terhadap pertumbuhan kacang panjang, (2) pengaruh bokshi terhadap } \\
\text { pertumbuhan kacang panjang, (3) pengaruh interaksi jenis mulsa dan dosis bokashi } \\
\text { terhadap pertumbuhan kacang panjang. Dalam penelitian ini digunakan rancangan } \\
\text { faktorial yang terdiri atas } 2 \text { faktor. Faktor pertama adalah jenis mulsa dan faktor } \\
\text { kedua adalah dosis bokashi. Data penelitian dianalisis dengan analisis sidik ragam } \\
\text { dan uji lanjut dengan Uji Beda Nyata Terkecil (BNT). Hasil penelitian menunjukkan } \\
\text { bahwa (1) jenis mulsa tidak berpengaruh nyata terhadap pertumbuhan kacang } \\
\text { panjang (2) dosis bokashi berpengaruh nyata terhadap pertumbuhan kacang panjang, } \\
\text { (3) interaksi jenis mulsa dan dosis bokashi tidak berpengaruh nyata terhadap } \\
\text { pertumbuhan kacang panjang. }\end{array}$ \\
\hline
\end{tabular}

\section{PENDAHULUAN}

Pertumbuhan dan produksi tanaman sangat ditentukan oleh ketersediaan unsur hara dalam tanah. Salah satu upaya yang dapat dilakukan untuk meningkatkan ketersediaan unsur hara adalah dengan melakukan pemupukan tanaman. Pemupukan tanaman dapat dilakukan dengan menggunakan pupuk organik seperti bokashi. Bokashi adalah pupuk kompos yang dihasilkan dari proses fermentasi atau peragian bahan organik dengan teknologi EM4 (Effective Microorganisms 4). Keunggulan penggunaan teknologi EM4 
adalah pupuk organik (kompos) dapat dihasilkan dalam waktu yang relatif singkat (Teruo, 1999).

Beberapa penelitian yang sudah dilakukan menunjukkan bahwa penggunaan bokashi berpengaruh nyata terhadap pertumbuhan tanaman. Pemberian bokashi pada lahan pertanian Desa Montong Are dapat meningkatkan produksi terong ungu (Raksun dan Mertha, (2018). Pemberian berbagai jenis bokashi memberikan pengaruh yang sangat nyata terhadap pertumbuhan dan hasil jagung manis (Mulyanti dkk, 2015). Pemberian bokashi berpengaruh nyata terhadap produsi padi (Raksun, 2018)

Mulsa adalah bahan yang dipakai untuk menutup permukaan tanah yang berfungsi untuk menghindari kehilangan air melalui penguapan dan menekan pertumbuhan gulma. Keberadaan mulsa sangat berperan terhadap pertumbuhan dan produksi taman. Hasil penelitian Junaidi dkk (2013) menunjukkan bahwa penggunaan mulsa dapat meningkatkan panjang tanaman, berat buah, lingkar buah, berat segar, dan berat kering buah semangka. Hasil terbaik adalah perlakuan mulsa plastik hitam perak dengan panjang tanaman $353,98 \mathrm{~cm}$, dan berat buah 5,47 kg. Demikian juga Wisudawati dkk (2016), menyimpulkan bahwa mulsa jerami padi dan mulsa plastik perak menghasilkan pertambahan tinggi tanaman tertinggi dan panjang daun terpanjang tanaman bawang merah pada umur 50 hari setelah tanam.

Berdasarkan uraian di atas maka peneliti melakukan penelitian tentang pengaruh jenis mulsa dan bokashi terhadap pertumbuhan kacang panjang yang dilakukan di Desa Sukarara Kecamatan Jonggat Kabupaten Lombok Tengah. Adapun tujuan dilaksanakannya penelitian ini adalah untuk mengetahui: (1) pengaruh jenis mulsa terhadap pertumbuhan kacang panjang, (2) pengaruh bokashi terhadap pertumbuhan kacang panjang, (3) pengaruh interaksi jenis mulsa dan bokashi terhadap pertumbuhan kacang panjang

\section{METODE}

Bahan-bahan yang digunakan dalam penelitian ini adalah bokashi, mulsa jerami padi, mulsa pelastik hitamperak, tanah sawah, insetisida, fungisida, ajir bambu dan air.
Selanjutnya alat-alat yang digunakan adalah cangkul, ember plastik, parang, gelas ukur, alat tulis menulis, timbangan, parang, hand spreyer, artco dorong dan gunting

Dalam penelitian ini digunakan rancangan faktorial yang terdiri atas 2 faktor. Faktor pertama adalah jenis mulsa yaitu: $\mathrm{M}_{1}=$ Mulsa jerami padi dan $\mathrm{M}_{2}=$ mulsa pelastik hitam perak. Faktor kedua adalah dosis bokashi yang terdiri atas 5 level, yaitu $\mathrm{B}_{0}=$ tanpa pemberian bokashi (kontrol), $\mathrm{B}_{1}=$ pemberian $0,6 \mathrm{~kg}$ bokashi $/ 1 \mathrm{~m}^{2}$ lahan, $\mathrm{B}_{2}=$ pemberian $1,2 \mathrm{~kg}$ bokashi $/ 1 \mathrm{~m}^{2}$ lahan, $\mathrm{B}_{3}=$ pemberian $1,8 \mathrm{~kg}$ bokashi $/ 1 \mathrm{~m}^{2}$ lahan dan $\mathrm{B}_{4}=$ pemberian 2,4 $\mathrm{kg}$ bokashi/1 $\mathrm{m}^{2}$ lahan. Setiap kombinasi perlakuan dilakukan dengan 4 ulangan dengan kombinasi perlakuan seperti Tabel 1:

Tabel 1. Kombinasi Perlakuan

\begin{tabular}{llllll}
\hline Perlakuan & $\mathrm{B}_{0}$ & $\mathrm{~B}_{1}$ & $\mathrm{~B}_{2}$ & $\mathrm{~B}_{3}$ & $\mathrm{~B}_{4}$ \\
\hline $\mathrm{M}_{1}$ & $\mathrm{M}_{1} \mathrm{~B}_{0}$ & $\mathrm{M}_{1} \mathrm{~B}_{1}$ & $\mathrm{M}_{1} \mathrm{~B}_{2}$ & $\mathrm{M}_{1} \mathrm{~B}_{3}$ & $\mathrm{M}_{1} \mathrm{~B}_{4}$ \\
$\mathrm{M}_{2}$ & $\mathrm{M}_{2} \mathrm{~B} 0$ & $\mathrm{M}_{2} \mathrm{~B}_{1}$ & $\mathrm{M}_{2} \mathrm{~B}_{2}$ & $\mathrm{M}_{2} \mathrm{~B}_{3}$ & $\mathrm{M}_{2} \mathrm{~B}_{4}$ \\
\hline
\end{tabular}

Parameter pertumbuhan yang diukur adalah panjang daun, lebar daun, dan panjang batang yang dilakukan setelah tanaman berumur 25 hari. Data kuantitatif hasil pengukuran parameter pertumbuhan kacang panjang dianalisis dengan analisis sidik ragam dan uji lanjut dengan Uji Beda Nyata Terkecil (Gomez \& Gomez, 1991)

\section{HASIL DAN PEMBAHASAN}

Data hasil pengukuran parameter pertumbuhan yang meliputi panjang daun, lebar daun dan panjang batang kancang panjang yang diukur 25 hari setelah tanam seperti Tabel 2:

Tabel 2. Data hasil pengukuran rerata panjang daun kacang panjang akibat perbedaan jenis mulsa dan perlakuan bokashi

\begin{tabular}{ll}
\hline Perlakuan & Panjang Daun $(\mathrm{mm})$ \\
\hline $\mathrm{M}_{1} \mathrm{~B}_{0}$ & 103 \\
$\mathrm{M}_{1} \mathrm{~B}_{1}$ & 105 \\
$\mathrm{M}_{1} \mathrm{~B}_{2}$ & 108 \\
$\mathrm{M}_{1} \mathrm{~B}_{3}$ & 112 \\
$\mathrm{M}_{1} \mathrm{~B}_{4}$ & 111 \\
$\mathrm{M}_{2} \mathrm{~B}_{0}$ & 103 \\
$\mathrm{M}_{2} \mathrm{~B}_{1}$ & 106 \\
$\mathrm{M}_{2} \mathrm{~B}_{2}$ & 110 \\
$\mathrm{M}_{2} \mathrm{~B}_{3}$ & 113 \\
$\mathrm{M}_{2} \mathrm{~B}_{4}$ & 113 \\
\hline
\end{tabular}


Hasil analisis sidik ragam menunjukkan bahwa perbedaan dosis bokashi berpengaruh nyata terhadap panjang daun kacang panjang. Perbedaan jenis mulsa dan interaksi jenis mulsa dan dosis bokashi tidak berpengaruh nyata terhadap panjang daun kacang panjang. Hasil uji Beda Nyata terkecil menunjukkan bahwa perlakuan $1,8 \mathrm{~kg} / 1 \mathrm{~m}^{2}$ lahan pertanian menghasilkan panjang daun kacang panjang tertinggi. Selanjutnya hasil pengukuran lebar daun kacang panjang terdapat pada Tabel 3

Tabel 3. Data hasil pengukuran rerata lebar daun kacang panjang akibat perbedaan jenis mulsa dan perlakuan bokashi

\begin{tabular}{ll}
\hline Perlakuan & Lebar Daun $(\mathrm{mm})$ \\
\hline $\mathrm{M}_{1} \mathrm{~B}_{0}$ & 59 \\
$\mathrm{M}_{1} \mathrm{~B}_{1}$ & 60 \\
$\mathrm{M}_{1} \mathrm{~B}_{2}$ & 63 \\
$\mathrm{M}_{1} \mathrm{~B}_{3}$ & 67 \\
$\mathrm{M}_{1} \mathrm{~B}_{4}$ & 67 \\
$\mathrm{M}_{2} \mathrm{~B}_{0}$ & 59 \\
$\mathrm{M}_{2} \mathrm{~B}_{1}$ & 63 \\
$\mathrm{M}_{2} \mathrm{~B}_{2}$ & 66 \\
$\mathrm{M}_{2} \mathrm{~B}_{3}$ & 68 \\
$\mathrm{M}_{2} \mathrm{~B}_{4}$ & 67 \\
\hline
\end{tabular}

Hasil analisis sidik ragam menunjukkan bahwa perbedaan dosis bokashi berpengaruh nyata terhadap lebar daun, perbedaan jenis mulsa dan interaksi jenis mulsa dan dosis bokashi tidak berpengaruh nyata terhadap lebar daun. Hasil uji Beda Nyata terkecil menunjukkan bahwa dosis optimum yang diperlukan adalah $1,8 \mathrm{~kg} / 1 \mathrm{~m}^{2}$ lahan pertanian. Selanjutnya hasil pengukuran panjang batang kacang panjang terdapat pada Tabel 4.

Tabel 4. Data hasil pengukuran rerata panjang batang kacang panjang akibat perbedaan jenis mulsa dan perlakuan bokashi

\begin{tabular}{ll}
\hline Perlakuan & Panjang batang $(\mathrm{cm})$ \\
\hline $\mathrm{M}_{1} \mathrm{~B}_{0}$ & 46 \\
$\mathrm{M}_{1} \mathrm{~B}_{1}$ & 53 \\
$\mathrm{M}_{1} \mathrm{~B}_{2}$ & 58 \\
$\mathrm{M}_{1} \mathrm{~B}_{3}$ & 62 \\
$\mathrm{M}_{1} \mathrm{~B}_{4}$ & 61 \\
$\mathrm{M}_{2} \mathrm{~B}_{0}$ & 46 \\
$\mathrm{M}_{2} \mathrm{~B}_{1}$ & 52 \\
$\mathrm{M}_{2} \mathrm{~B}_{2}$ & 58 \\
$\mathrm{M}_{2} \mathrm{~B}_{3}$ & 63 \\
$\mathrm{M}_{2} \mathrm{~B}_{4}$ & 62 \\
\hline
\end{tabular}

Hasil analisis sidik ragam menunjukkan bahwa perbedaan dosis bokashi berpengaruh nyata terhadap panjang batang, perbedaan jenis mulsa dan interaksi jenis mulsa dan dosis bokashi tidak berpengaruh nyata terhadap panjang batang. Selanjutnya hasil uji Beda Nyata terkecil menunjukkan bahwa dosis optimum yang diperlukan adalah $1,8 \mathrm{~kg} / 1 \mathrm{~m}^{2}$ lahan pertanian.

Data pada tabel 1, 2 dan 3 menunjukkan bahwa kacang panjang yang tumbuh pada lahan percobaan tanpa perlakuan bokashi memiliki rerata panjang daun, lebar daun dan tinggi batang terendah (masing-masing adalah $103 \mathrm{~mm}, 59 \mathrm{~mm}$ dan $46 \mathrm{~cm}$. Selanjutnya pada lahan yang diberi perlakuan bokashi secara umum memiliki rerata panjang daun, lebar daun dan tinggi batang yang meningkat sejalan dengan meningkatnya dosis bokashi yang diberikan. Namun demikian mulai dari perlakuan B3 sampai dengan B4, rerata panjang daun, lebar daun dan tinggi batang tidak mengalami peningkatan secara signifikan.

Meningkatnya panjang daun, lebar daun dan tinggi batang kacang panjang akibat pemberian bokashi pada lahan pertanian diduga disebabkan karena aplikasi bokashi dapat meningkatkan ketersediaan unsur hara terutama unsur hara nitrogen. Miller dan Roy (1990) menjelaskan bahwa bahan organik tanah merupakan sumber nitrogen hingga 90 95\% pada tanah yang tidak subur. Bahan organik dapat juga bertindak sebagai khelat yang sangat membantu unsur hara mobil menjadi unsur hara yang tersedia bagi tanaman.

Hasil penelitian ini sejalan dengan hasil penelitian yang dilakukan oleh sejumlah peneliti lainnya. Pemberian bokashi berpengaruh sangat nyata terhadap tinggi dan berat segar tanaman caisin (Tomia, 2012). Pemberian berbagai jenis bokashi memberikan pengaruh yang sangat nyata terhadap pertumbuhan dan hasil jagung manis (Mulyanti dkk, 2015). Pemupukan bokashi dengan dosis 20 ton per hektar memberikan bobot gabah kering per hektar tertinggi $(4,70$ ton), jumlah anakan produktif tertinggi $(25,00)$ dicapai varietas cianjur (Mulyana dkk, 2011).Pemberian bokashi berpengaruh nyata terhadap pertumbuhan dan produksi tomat pada lahan pertanian Desa Pijot (Raksun dan Santoso, 2010). Pemberian pupuk bokashi Eceng Gondok menunjukkan respon sangat 
nyata pada total produksi kedelai per plot (Hasibuan dkk, 2017). Penambahan bokashi dalam dosis $250 \mathrm{~g}$ pada media tanah NPK dapat mendukung pertumbuhan cabe var. Inko 99 lebih optimal dengan tinggi tanaman 71,15 $\mathrm{cm}$ dan jumlah cabang produktif 40,75 buah (Gustia, 2009). Pemberian berbagai dosis bokashi berpengaruh nyata terhadap tinggi tanaman kedelai (Simaptupang, 1999). Pemberian bokashi pada lahan pertanian dapat meningkatkan pertumbuhan cabai merah (Raksun, 2009). Aplikasi bokashi berpengaruh pada pertumbuhan vegetatif dan produksi rumput gajah. Bokashi 30 ton per hektar memberikan pertumbuhan vegetatif dan produksi rumput gajah tertinggi (Kusuma, 2013). Media terbaik untuk pertumbuhan semai eboni adalah pupuk organik EM bokashi karena media ini dapat meningkatkan solubilitas dan viabilitas hara dalam tanah dan memberikan pertumbuhan semai eboni yang optimal (Sumiasri dan Setyowati, 2006).

Rendahnya tinggi batang, panjang daun dan lebar daun kacang panjang pada media tanpa pemberian bokashi diduga disebabkan oleh kurang optimalnya ketersediaan berbagai unsur hara pada lahan pertanian Desa Sukarare. Selanjutnya aplikasi bokashi menyebabkan makin tersedianya unsur hara terutama sulfat dan nitrat yang berasal dari hasil degradasi sampah organik yang dijaikan bahan baku pembuatan bokashi. Hasil Uji Beda Nyata Terkecil menunjukkan bahwa kadar optimum bokashi yang perlu diberikan pada lahan pertanian Desa Sukarare untuk meningkatkan pertumbuhan kacang panjang adalah $1,8 \mathrm{~kg}$ bokashi untuk setiap $1 \mathrm{~m}^{2}$ lahan pertanian, karena perlakuan dengan dosis 1,8 $\mathrm{kg}$ bokashi $/ 1 \mathrm{~m}^{2}$ lahan memberikan tingkat pertumbuhan kacang panjang yang terbaik dibandingkan perlakuan yang lain.

\section{KESIMPULAN}

Berdasarkan hasil analisis data dan pembahasan pada penelitian ini maka dapat disimpulkan bahwa: (1) Perbedaan jenis mulsa tidak berpengaruh nyata terhadap pertumbuhan kacang panjang. (2) Aplikasi bokashi berpengaruh nyata terhadap pertumbuhan kacang panjang, (3) Interaksi jenis mulsa dan dosis bokashi tidak berpengaruh nyata terhadap pertumbuhan kacang panjang. (4) Dosis terbaik bokahi untuk pertumbuhan kacang pajang pada lahan pertanian Desa Sukarare adalah 1,8 kg bokashi untuk $1 \mathrm{~m}^{2}$ lahan pertanian

\section{DAFTAR PUSTAKA}

Gomez K.A. dan A.A. Gomez. 1995. Prosedur Statistik Untuk penelitian Pertanian Edisi Kedua Penerjemah: Endang Syamsudin dan Justika S. Baharsyah. UI Press. Jakarta.

Gustia, H. 2009. Pengaruh pemberian Bokashi Terhadap pertumbuhan dan produksi tanaman cabe var. inko-99. Akta Agrosia Vol. 12(2) p. 113 - 123.

Hasibuan, S., Mawarni, R., Hendriandri, R. 2017. Respon Pemberian Pupuk Bokashi Ampas Tebu dan Pupuk Bokashi Eceng Gondok terhadap Pertumbuhan dan Produksi Tanaman Kedelai. Bernas 13(2) p. $59-64$

Junaidi I., Santoso, S.J. dan Sudalmi, E.S. 2013. Pengaruh Macam Mulsa dan Pemangkasan terhadap Pertumbuhan dan Hasil Tanaman Semangka. Inovasi Pertanian Vol 12 (2) p. 67 - 84

Kusuma, M.E, 2013. Respons of Bokashi on the Vegetative Growth and roduction of Elephant Grass (Pennisetum purpureum). Ilmu Hewani Tropika. Vol 2 (2) p. 40 - 45

Miller, RW. And L.D. Roy. 1990. Soil and Plant Growth. Sixth ed. Frentice-Hall International. Inc. New Jersey.

Mulyana, D., Sahidin dan Iqbal, A. 2011. Pengaruh Dosis Bokashi terhadap Pertumbuhan dan Hasil Tiga Varietas Padi. Agrin Vol 15(1) p. 18 - 26

Mulyanti, S.S., Made, U. dan Wahyudi, I. Pengaruh Pemberian Berbagai Jenis Bokashi terhadap Pertumbuhan dan Hasil Jagung Manis (Zea mays Saccarata). Agrotekbis Vol 3(5) p. 592 $-601$

Raksun, A. 2018. Pengaruh Bokashi Terhadap Produksi Padi (Oryza sativa L). Jurnal Penelitian Pendidikan IPA Vol 4 (1) p. $64-67$ 
Raksun, A. dan Mertha, I. G. 2018. Pengaruh Bokashi terhadap Produksi Terong Ungu (Solanum melongena L). Biologi Tropis Vol 18 (1) p. $21-26$

Sumiarsi, N dan Setyowati, 2006. Pengaruh beberapa Media TerhadapPertumbuhan Bibit Eboni (Diospyros celebica Bakh). Melalui Perbanyakan biji. Biodipersitas. Vol 7(3) p. 260-263

Tomia, A. 2012 Pemanfaatan Bokashi Kotoran Ternak Ayam terhadap Produksi Tanaman Caisin. Agribisnis dan perikanan (Agrikan). Vol 5 (2) p. 20 24

Wisudawati, D., Anshar, M. dan Lapanjang I. Pengaruh Jenis Mulsa terhadap Pertumbuhan dan Hasil Bawang Merah yang Diberi Sungkup. Agrotekbis. Vol 4 (2) p. 126 - 133 